\title{
Contabilidade: dos escândalos à renovação
}

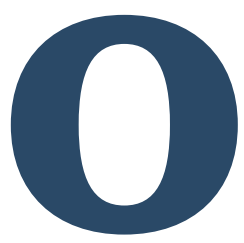

avanço da informatização na sociedadee nas empresas está modificando o trabal ho de contabilidade. Paradoxalmente, no lugar de consolidar sua tradição normativa e sua imagem associada à objetividade, o que tal processo está provocando é justamenteo contrário: a contabilidadeestáse tornando cada vez mais subjetiva. Essa tendência abre duas grandes rotas: a primeira éo enriquecimento do trabalho na área, que passa a ser menos operacional e mais analítico; e a segunda é a necessidade de buscar maior transparência da informação contábil.

por Eduardo Diniz FGV-EAESP e Alexsandro Broedel Lopes FEA-USP

Q uando os escândalos contábeis, ocorridos em grandes empresas norte-americanas e européias - Enron, WordCom e outras - , chegaram à mídia, muitos observadores voltaram-se para os processos de contabilidade e auditoria dessas empresas. Sinais de manipulação da infor- mação e corrupção foram identificados e exaustivamente discutidos. Uma grande empresa de auditoria - a Arthur Andersen - desapareceu em função de seu envolvimento com o caso Enron, e a regulamentação da atividade dos auditores foi reformulada. 
Entre diversos outros aspectos, os escândalos chamaram a atenção para uma questão singular: o processo contábil, geralmente considerado como objetivo e meticuloso, havia servido para mascarar a real situação das empresas. As informações contábeis, tidas como exatas e indiscutíveis, mostraram-se volúveis e abertas à interpretação. Chegou-se inclusive a cunhar o termo "contabilidade criativa", uma contradição em termos, sob a visão mais tradicional. A sensação de que "práticas não ortodoxas" estariam acontecendo em centenas de outras grandes empresas foi alimentada pelo anúncio sucessivo de revisões de balanços, abalando a confiança no sistema financeiro.

Modelo em cheque. Mas há algo além do que práticas temerárias por trás dos escândalos: 0 fato é que a contabilidade não acompanhou a evolução do contexto de negócios. 0 processo contábil das empresas sempre foi focado em regras e procedimentos formais. Porém, a sofisticação da gestão financeira e 0 avanço dos sistemas de informação modificaram o contexto original ao qual essas regras e procedimentos se adequavam.

\section{Os escândalos financeiros ocorridos}

\section{recentemente chamaram a atenção}

\section{para mudanças substantivas no}

\section{contexto das práticas contábeis.}

Portanto, é preciso mudar o modo de como se vêem as práticas contábeis. A contabilidade deve deixar de ser uma área de geração de relatórios para ser uma área de suporte aos processos decisórios. Para isso, ela deve compreender a realidade de cada negócio, de forma a suprir os executivos com as informações necessárias - objetivas esubjetivas - para a tomada de decisão. Por outro lado, os executivos devem reconhecer a subjetividade inerente à informação contábil, no lugar de pressupor erroneamente a total objetividade.

Impactos da informatização. Criados, originalmente, para realizar cálculos, os computadores foram dissemi- nados nas empresas graças à necessidade de ganhar agilidade nos processos contábeis. Com o tempo, a informatização trouxe mais flexibilidade e agilidade na manipulação dos dados contábeis, permitindo análises cada vez mais complexas sobre a situação das empresas.

0 fenômeno pode ser observado na redução do número de trabalhadores em áreas de contabilidade nas empresas. Em 1985, os bancos no Brasil empregavam cerca de 33 mil contabilistas. Em 2000, esse número foi reduzido para pouco mais de 2 mil. Por outro lado, se o computador realiza os cálculos, as análises exigem cada vez mais a interferência de profissionais qualificados. Houve um aumento significativo, de 1985 a 2000, de 16 mil para 28 mil o número de gerentes empregados nos mesmos bancos. Essa mudança reflete uma alteração na forma como as informações contábeis são geradas e utilizadas.

Diante desse quadro, se a contabilidade se limitar à mera coleta e organização de informações, seu escopo e sua contribuição serão irremediavelmente restringidos. Para romper tais limites, surgiu a "infotabilidade", a contabilidade que agrega valor aos negócios pelo uso inteligente da informática e pela agregação da competência analítica. A "infotabilidade" utiliza a base informacional, mas vai além dela, discorrendo sobre os aspectos subjetivos do tratamento das informações contábeis.

Novo papel. N esse cenário, o papel da contabilidade passa a ter valor prospectivo e característica subjetiva. Defato, as principais informações contá-

beis, aquelas que podem demonstrar o potencial de um determinado negócio, já são prospectivas. As únicas informações objetivas que constam das demonstrações contábeis de uma empresa referem-se à data de publicação, ao sal do em caixa e ao número de ações em poder do público. Todas as demais informações, como provisão para devedores duvidosos, depreciação, diferimento e ágio são subjetivas e prospectivas.

A contabilidade, ou "infotabilidade", somente terá relevância à medida que agregar valor à informação pela realização de análises. Essa tarefa deve levar em conta as necessidades do usuário e o tipo de informação que ele deseja obter. Com isso, o processo contábil ganhará status estratégico. 
As exigências endereçadas hoje à contabilidade a impedem de ser uma contabilidade que visa a informar apenas 0 fisco, por exemplo. Tal prática poderia ser traduzida como uma tendência "hermafrodita" da contabilidade, quando ela se basta a si mesma, numa relação de contador para contador. Além de apoiar os processos decisórios internos e de subsidiar as ações tradicionais da contabilidade (balanços, situação da empresa perante o fisco etc.), ela deve estar voltada para informar o acionista e o público externo.

Isso implica preparar a informação contábil com a dose certa de amplitude e profundidade, e em uma linguagem de acesso aos diversos agentes envolvidos (mercado, acionistas etc.). Cabe esclarecer: quando se fala em amplitude de informação contábil, entende-se o grau de abertura (disclosure) das operações off-balance, como a verificação do quanto as escolhas estratégicas são coerentes e consistentes e quais as principais práticas e políticas contábeis da empresa.

Mercado de capitais. A integração entre o campo da gestão de informações e a contabilidade pode também ser observada no mercado de capitais. Os processos contábeis são, na realidade, intermediários informacionais. E eles são essenciais para que outros intermediários, os financeiros (bancos, seguradoras e fundos de investimento), possam cumprir seu papel. Os intermediários financeiros captam recursos dos agentes econômicos superavitários e direcionam tais recursos para as melhores oportunidades de investimento: os agentes deficitários. Para que os intermediários financeiros possam selecionar adequadamente as meIhores oportunidades, eles precisam ver quebrada a assimetria informacional - as diferenças entre as informações detidas pelos diversos agentes do mercado - que existe entre os investidores e os gestores das organizações deficitárias em capital.

Os investidores não conseguem, a priori, diferenciar empresas boas e ruins. Os administradores, por seu lado, sabem a real situação de suas empresas. Assim, eles precisam enviar sinais ao mercado sobre suas empresas.

Dessa forma, os intermediários informacionais podem agregar valor de duas maneiras: produzindo e atestando a qualidade da informação. Auditores somente atestam um aspecto da qualidade da informação - a conformidade com

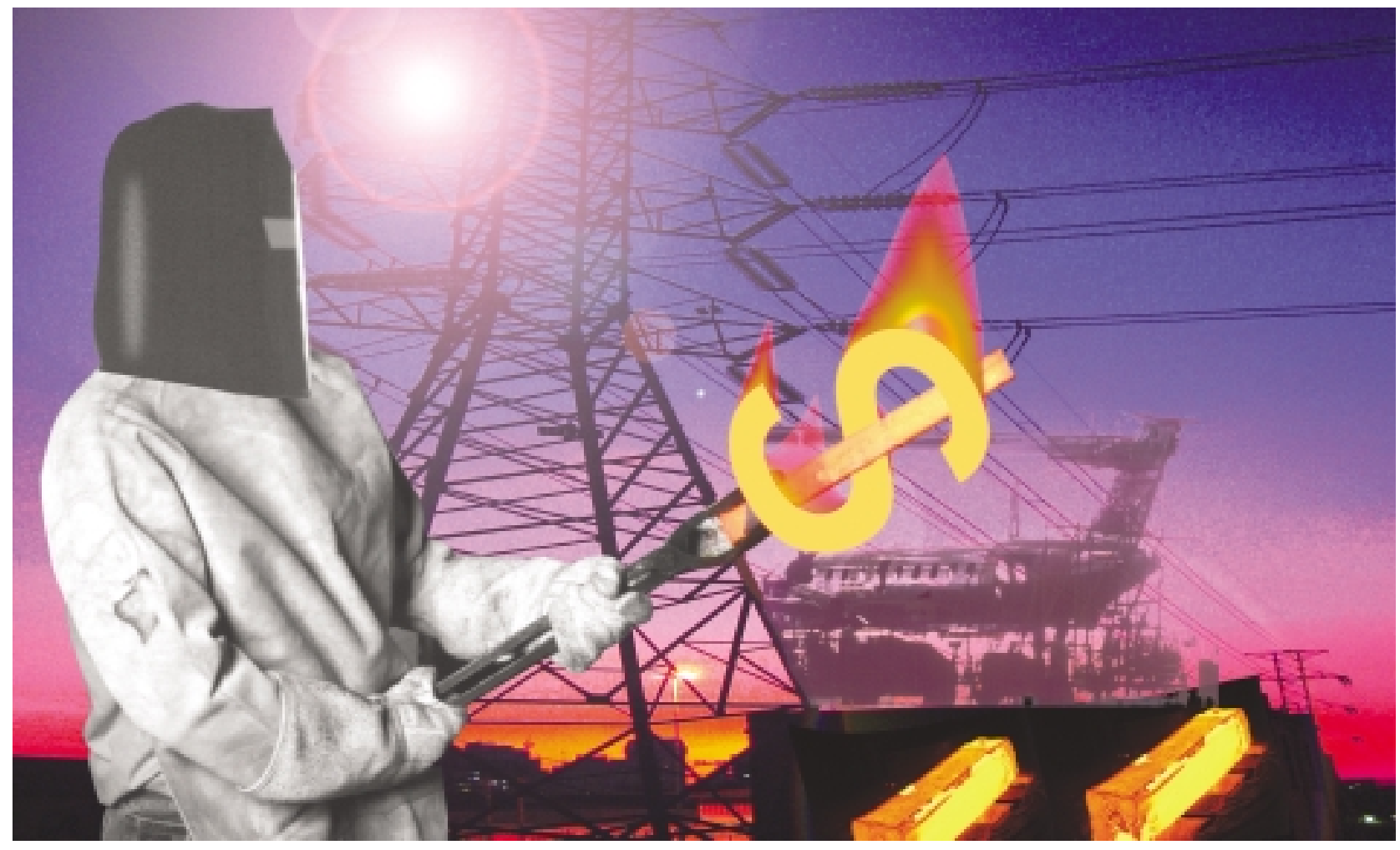


os princípios contábeis. Analistas de crédito, por outro lado, produzem novas informações. A partir de balanços publicados e de uma análise da conjuntura econômica, eles atribuem notas (ratings) às empresas de acordo com a capaci-
Valor agregado. Como vimos, a contabilidade deve agregar valor à informação. E esse valor deve ser adicionado, principalmente, por intermédio da geração de conhecimento com base nas demonstrações contábeis.

\section{A contabilidade deve vencer sua tendência}

\section{"hermafrodita", de se bastar a si mesma, e}

\section{passar a atender as necessidades de informação}

\section{dos executivos e do mercado financeiro.}

dade de elas honrarem compromissos no futuro. 0 mesmo fazem os analistas de investimentos (equity research).

Deve ser também considerado o papel da contabilidade no desenvolvimento do mercado de capitais. Parece haver unanimidade entre os economistas no que concerne ao papel desse mercado para o desenvolvimento econômico. Sem mercados de capitais ativos, as empresas não conseguem obter financiamentos de longo prazo com taxas de juros aceitáveis. Dessa forma, elas são obrigadas a realizar projetos com prazos mais curtos e com menor risco.

Esse fato é ilustrado pela extensa utilização do payback como método de avaliação de projetos de investimento no Brasil. Ora, os projetos de maior duração e com maior risco são os que oferecem maiores oportunidades de retorno e, conseqüentemente, podem agregar mais valor para a economia.
O corre que a expectativa do resultado econômico esperado é composta pelo fluxo de caixa projetado e por uma parte subjetiva, derivada da sensibilidade e da capacidade de interpretação do analista contábil.

Essa parte subjetiva é o chamado accrual (regime de competência), no qual reside 0 conteúdo informativo da contabilidade. Assim, para que o mercado de capitais possa florescer, é preciso que a assimetria informacional entregestores e investidores possa ser quebrada e que estes últimos consigam avaliar adequadamente as melhores alternativas de investimento.

O novo papel da contabilidade, aqui discutido, leva-nos a refletir sobre o impacto estratégico da geração e interpretação das informações contábeis. Os escândalos que ocorreram no ano passado com grandes empresas norte-americanas eeuropéias mostram-nos como a informação podeser manipulada, justamente ondese pensava reinar a racional idadee a fidelidade de dados. Em uma época em que a informação se torna um dos principais motores dos negócios, descartar 0 poder de interpretação sobre ela e a subjetividadeé perder de vista a capacidade de agir sobre cenários futuros e potenciaise,

\section{Ótica dupla}

Um exemplo de depreciação de equipamentos ajuda a compreender as diferentes perspectivas da contabilidade.

Uma empresa possui em seus ativos somente máquinas e equipamentos no valor de $\mathrm{R} \$ 100$ mil. Ela deve depreciá-los devido ao regime de competência que atribui perda de valor econômico do bem em função de sua efetiva utilização.

$\mathrm{Na}$ abordagem tradicional, o contador segue as regras estabelecidas por um órgão regulador, sem se preocupar se essa depreciação realmente reflete a perda de valor econômico do bem. Sob a nova abordagem, a depreciação deve ser vista como uma excelente oportunidade de comunicação.
O contador e os administradores podem usar esse lançamento contábil para informar ao mercado a real situação de seus ativos, quebrando, assim, a assimetria informacional. Para isso, ele não deve usar uma métrica de depreciação preestabelecida. 0 mais adequado é avaliar caso a caso e informar realmente quanto de valor econômico foi perdido naquele período. Alguns poderiam sugerir que essa é uma informação subjetiva. Sem dúvida, ela é mesmo subjetiva. No entanto, é a subjetividade que guarda o grande valor da contabilidade. 
no caso particular aqui discutido, de transformar a contabilidade em uma linguagem de mediação entre a empresa e seu público externo, por meio da geração de informação contábil que, de fato, gere valor estratégico ao negócio.

Eduardo Henrique Diniz

Prof. do Departamento de Informática e Métodos Q uan- titativos da FGV-EAESP

Doutor em Administração pela FGV-EAESP

E-mail: ediniz@fgvsp.br

Alexsandro Broedel Lopes

Prof. do Departamento de Contabilidade e Atuária da FEA-USP Doutor em Controladoria e Contabilidade pela FEA-USP

E-mail: broedel@usp.br

\section{O Fim do guarda-livros}

Depois dos escândalos contábeis ocorridos recentemente, a contabilidade foi trazida para 0 primeiro plano das preocupações das empresas. Nesta entrevista, cedida a Pedro Bendassolli, da RAE-executivo, o contador Antoninho Marmo Trevisan comenta as principais mudanças e desafios para a contabilidade hoje.

Quais foram os incidentes críticos que mais contribuíram para a mudança no papel da contabilidade?

Desde seus primórdios, a contabilidade vem se adaptando à realidade econômica em cada país. Com o evento da globalização, ela está caminhando para a universalização das práticas contábeis. Portanto, nunca foi uma ciência "acomodada". É lógico que os grandes escândalos financeiros ocorridos em um passado recente, como, por exemplo, a crise asiática e a norte-americana, aceleraram essas mudanças visando a uma maior transparência e segurança das informações divulgadas. Por isso, classificaria esses incidentes como uma oportunidade, pois a abertura de mercado trouxe a necessidade de os empresários estarem atualizados em relação às atividades de sua organização, em relação à performance da empresa e em relação ao mercado.

Como a informação contábil é hoje usada no mercado?

Como sempre, ela é utilizada para analisar os diversos índices de lucratividade, retornos, giros, EBITDA etc. É utilizada, também, para se obter informações comparativas entre empresas do mesmo segmento. Internamente, as empresas mais sérias utilizam-na como instrumento de gestão. A informação contábil é um sistema de avaliação destinado a prover seus usuários de demonstrações e análises de natureza econômica, financeira, física e de produtividade, com relação à entidade objeto de contabilização.

Um bom contador é apenas alguém que domina muito bem o manejo de números? Ou agora é preciso algo mais em termos de competências?

Com a globalização iniciada na década de 1990, o contador deixou de ser o "guarda-livros" da companhia. Hoje, o contador, além de manejar os números, analisa as demonstrações financeiras, toma decisões e discute idéias para manter a companhia em atividade normal de suas operações.
Como deve ser feita, hoje, a comunicação entre o contador e a empresa? Como transmitir a informação contábil?

A comunicação entre 0 contador e a empresa deve ser a mais transparente possível, pois hoje o contador assume a responsabilidade por informações incorretas nas demonstrações contábeis. A informação deve ser transmitida por meio de relatórios contábeis e gerenciais, nos quais o usuário das demonstrações contábeis consiga traduzir essas informações e avaliar a situação e o progresso de determinada entidade.

0 que mudou na prática contábil depois dos escândalos de $2001 / 2002$ ?

Não houve uma mudança drástica, mas sim um reforço e uma cobrança maior do que já era exigido, como por exemplo:

- Fazer com que as informações das demonstrações contábeis sejam claras para o entendimento do usuário;

- Proibição para que as empresas de auditoria independente prestem serviços de consultoria para a mesma empresa em que se está prestando trabalhos de auditoria externa;

- Maior rigor jurídico com os administradores da entidade;

- Maior ética profissional, no sentido de tratar as informações com acuidade e transparência perante clientes e público externo.

Quais as novas tendências no papel do contador na empresa? 0 contador tem um papel primordial na elaboração das demonstrações contábeis e é responsável pelas informações prestadas, respondendo criminalmente a quaisquer erros ou omissões de informações. Portanto, tenderá a ser mais independente em relação à administração geral, mais atualizado tecnicamente e com um papel mais ativo nas decisões estratégicas. Em suma, pode-se dizer que 0 contador terá um papel de consultor e assessor, já que tem, cada vez mais, uma visão geral da empresa e dos negócios. e-mail: pedrofernando@terra.com.br 